\title{
The Prevalence of Inducible Clindamycin Resistance Staphylococcus aureus among Various Clinical Specimens in Khartoum state Sudan
}

\author{
Safana A. A. Alhady ${ }^{1}$, Musa Abdalla Ali ${ }^{2}$ \\ 'Department of Microbiology, Alneelain University, Khartoum, Sudan \\ ${ }^{2}$ Department of Microbiology, University of Khartoum, Khartoum, Sudan
}

\begin{abstract}
Article Info

Volume 8, Issue 5

Page Number : $13-21$

Publication Issue :

September-October-

2021

\section{Article History}

Accepted : 01 Sep 2021

Published: 04 Sep 2021

Background : $S$. aureus is frequently associated with skin infections, pneumonia, surgery wounds, bacteraemia, osteomyelitis and endocarditis, being considered one of the most important pathogens of the human being, both at the community level and at nosocomial infections, and may become serious if caused by antimicrobial resistant strains, especially methicillin-resistant $\mathrm{S}$. aureus (MRSA) strains, which are resistant to most of the antimicrobial agents, methicillin-sensitive S.aureus (MSSA) and isolates with reduced susceptibility and resistance to vancomycin, which is the last drug for the treatment of MRSA infections. So, this study aimed to detect the existence of inducible resistance of S. aureus to Clindamycin in Khartoum-Sudan among patients attended to Suba University Hospital.
\end{abstract}

Methods : The study was performed as cross-sectional one, 53 clinical isolates of S. aureus obtained from (34 females and 19 males) with different clinical condition among patients attended to Suba University Hospital in KhartoumSudan from April to August 2017. To detect inducible clindamycin resistant by using D test. In addition to that MRSA / MSSA all the isolates screened for methicillin resistant by using $1 \mu \mathrm{g}$ oxacillin then examined for inducible clindamycin resistant by $\mathrm{D}$ test. In addition to that examine for antimicrobial susceptibility profile which include vancomycin, gentamycin, tetracycline and co-trimoxazole. The data were analyzed using Statistical Package for Social Science, version 22 , P. value $<0.05$ was considered statistically significant

Results : out of 53 isolates, $36 \mathrm{~S}$. aureus isolated resistant to Clindamycin, 26 (72.2\%) were MRSA and $10(27.8 \%)$ were MSSA by means of D test, while 17 (32.1\%) of isolates were sensitive 9 (53\%) MRSA and 8 (47\%) MSSA. Comparing Induced clindamycin resistance showed equally distribution among MSSA and MRSA isolates, giving no significant difference as $\mathrm{P}$ - value 0.167 .

Conclusion : This study showed that D.test to detect inducible clundamycin resistance in staphylococcus aureus.

Keywords : Staphylococcus Aureus, Inducible Clindamycin Resistance (iCR). 


\section{INTRODUCTION}

S. aureus is one of the most frequent causes of bacterial infections in skin, bone, tissue, and blood, with bacteremia being one of the most severe presentations (1), or as a marker of severe infections (2). Bacteremia refers to viable bacteria in the blood; it can be asymptomatic which occurs in normal daily activities such as conducting oral hygiene and after minor medical procedures. In a healthy person, these clinically benign infections are transient without further sequelae. But, when immune response mechanisms fail or become overwhelmed, bacteremia becomes a bloodstream infection that can evolve into many clinical spectrums and is differentiated as septicemia. Untreated and clinically significant bacteremia progresses to systemic inflammatory response syndrome (SIRS), sepsis, septic shock, and multiple organ dysfunction syndromes (MODS) (35). Bacteremia may be the best-described manifestation of S. aureus infection, it has been recognized that, the prevalence, prognosis, and outcome of $\mathrm{S}$. aureus bacteremia (SAB) in industrialized regions of the world (6). SAB is often associated with severe complications, such as secondary deep infections, and a reported mortality rate of $20-25 \%$ (7). However, nearly half of cases are classified as uncomplicated infections associated with a significantly lower risk of relapse and death (8-9). Uncomplicated $\mathrm{SAB}$ is partly due to in-hospital infections related to invasive procedures and the use of peripheral and central venous catheters, as well as community-acquired skin and soft tissue infections $(10,11)$. The extensive use of antibiotics worldwide is closely related to the increasing issues of antimicrobial resistance and antibiotic-associated infections $(12,13)$.

As $S$. aureus is the one of the most common organisms causing nosocomial (infections occurred in hospitals) and community-acquired infections in every region of the world, so increasing prevalence of resistance among Staphylococci is an increasing problem(4) The emergence of community-associated methicillinresistant Staphylococcus aureus (MRSA) infections in the late $1990 \mathrm{~s}(14,15)$ resulted in a shift in the recommendations for antimicrobial therapy for staphylococcal infections from penicillinase-resistant $\beta$-lactam agents active against methicillinsusceptible $S$. aureus (MSSA) to other drugs included clindamycin(21-25) . So, Clindamycin is not recommended for any infection caused by an inducible resistant isolate. MRSA isolates with inducible clindamycin resistance (iCR) are resistant to erythromycin and sensitive to clindamycin on routine testing. D-test can help to determine whether clindamycin could be used as a therapeutic option (26).

Clindamycin is a food and drug agency (FDA)approved for the treatment of septicemia, intraabdominal infections, lower respiratory infections, gynecological infections, bone, and joint infections, and skin and skin structure infections as well as in the treatment of streptococcal pharyngitis, acne vulgaris, bacterial vaginosis, and severe pelvic inflammatory disease(27) Clindamycin acting through preventing peptide bond formation, so inhibiting protein synthesis by reversibly binding to $50 \mathrm{~S}$ ribosomal subunits. Depending on the organism, infection site, and drug concentration, clindamycin may be a bacteriostatic or bactericidal antibiotic. Administrated orally, absorption cannot take place until clindamycin palmitate becomes hydrolyzed in the gastrointestinal (GI) tract. It then distributes across the body in tissue and other regions containing blood. Clindamycin cannot efficiently penetrate meninges very well and is therefore not an antibiotic of choice for infections of the cerebrospinal fluid (CSF). As it travels through the bloodstream, clindamycin is primarily bound to protein (27-30).

Development of drug resistance in $S$. aureus has led to the use of older antibiotics such as macrolide, lincosamide, and streptogramin B (MLSB) antibiotic 
(31-33). So extensive use of these antibiotics in serious staphylococcal infections has caused the emergence of $S$. aureus resistant to MLSB antibiotics (34). Resistance occurs by different mechanisms to these microbiologically related antibiotics. Resistance due to active efflux encoded by $m s r(\mathrm{~A})$ gene confers resistance to macrolides and streptogramin $\mathrm{B}$ (MS phenotype) but not to clindamycin. Ribosomal target modification, another mechanism of resistance, confers resistance to macrolide, type B streptogramin and also to clindamycin (MLS в phenotype). $\mathrm{MLS}_{\mathrm{B}}$ resistance in staphylococci is either constitutive $\left(\mathrm{cMLS}_{\mathrm{B}}\right)$, where rRNA methylase is always produced or inducible $\left(\mathrm{iMLS}_{\mathrm{B}}\right)$, where methylase is only produced in the presence of an inducer, and is encoded by erm (A) or erm (C) gene (35-36). Patients

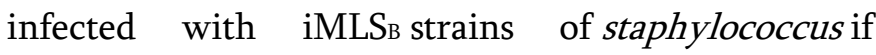
treated with clindamycin can develop constitutive resistance during therapy and subsequently result in treatment failure (37).

Strains with inducible resistance to clindamycin are difficult to detect in the routine laboratory (38), so lack of identity of inducible clindamycin resistance leads to false laboratory reports and could lead to clinical failure when clindamycin is used therapeutically and cause treatment problems (39-40). On the other hand, labeling of staphylococci as clindamycin resistant, while they are only resistance to erythromycin, could stop prescription of clindamycin, in cases that infections have occurred by truly clindamycin-susceptible staphylococcal isolates (38-41). A simple laboratory test (as titled D-zone test) can differentiate between staphylococci that have inducible erm genes-mediated resistance and those which have efflux pump-mediated resistance (42).

\section{MATERIAL AND METHOD}

This study was cross sectional study conducted during 5 months from April to August 2017, of targeting patients admitted in Soba Universal hospital. Patients were 53, females' contributors were 34(64.2\%), while
19 (35.8\%) males were involved. Collecting different samples, they were processed to isolate $S$. aureus, included pus, body fluids, and urine. S. aureus isolates were identified by standard biochemical techniques (43). Bacteria were sub cultured on Manitol Salt Agar then followed by aerobic overnight incubation at $37^{\circ} \mathrm{C}$. The isolates were re- identified based on colonial morphology, Gram's stain, and other biochemical tests according to the Gram Stain. Detection of MRSA: Oxacillin susceptibility testing was performed with $1 \mu \mathrm{g}$ oxacillin disks on Mueller Hinton Agar, incubated aerobic overnight at $37^{\circ} \mathrm{C}$. The interpretation of the bacterial susceptibility results was recorded as "resistant," intermediate and "sensitive." The antibiotic susceptibility was determined according with methods of Clinical and Laboratory Standards Institute (CLSI) for the purpose of the study

Antimicrobial susceptibility testing was done by Kirby-Bauer's disc diffusion method using various antimicrobial agents like Vancomycin (30 $1 \mu \mathrm{g})$, oxacillin (1 g), gentamycin (10 g), erythromycin (15 $\mathrm{g}$ ), as per CLSI guidelines (44). For detection of methicillin resistance, $1 \mathrm{~g}$ of oxacillin disc was placed; plates were incubated at $35^{\circ} \mathrm{C}$ for $24 \mathrm{~h}$. Isolates with zone diameters $\leq 10 \mathrm{~mm}$ was labeled as methicillin resistant (43). For detection of inducible clindamycin resistance, a disk approximation test was performed by placing a $2 \mathrm{mg}$ clindamycin disc from $19 \mathrm{~mm}$ away from the edge of a $15 \mathrm{mg}$ erythromycin disc. Following overnight incubation at $37^{\circ} \mathrm{C}$.

Inducible clindamycin resistance was confirmation by forming of a flattening shape of the clindamycin inhibition zone ( $\mathrm{D}$ shape) around the erythromycin disk which indicated erythromycin had induced clindamycin resistance. Furthermore, the staphylococcal isolates were grouped to two different phenotypes, these phenotypes were: $\mathrm{D}$ positive phenotype (inducible resistant to clindamycin and Resistant for erythromycin) and D Negative (Sensitive for both erythromycin and clindamycin). 


\section{RESULTS AND DISCUSSION}

In this study a total of $53 \mathrm{~S}$. aureus isolates were collected from samples (pus, urine and body fluids) of $34(64.2 \%)$ females and 19 (35.8\%) males as in Figure 1.

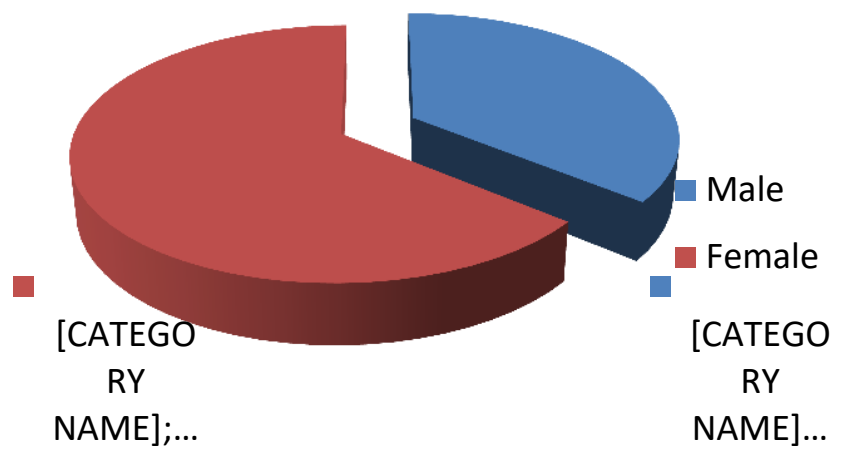

The distribution of isolates among males and females did not showed statistically significant difference as $\mathrm{p}$ value $=0.302$ (significant difference obtained when $p$ value $<0.05)$.

Majority of isolated S. aureus were obtained from pus (50\%) followed by urine (23\%); blood and body fluids (27\%). A total of $36(67.9 \%) \mathrm{S}$. aureus isolates were resistant to Clindamycin. Other antibiotic was included as they were set at the disc, so S. aureus isolates sensitive to vancomycin 51(96.2\%), Gentamycin38 (71.7\%), and Tetracycline31 (58.5\%) and Co-Trimoxazole 35(66.0\%) as in table 1.

Figure 1 : shows the distribution of gender across the study participants.

Table 1 : Antimicrobial Susceptibility Profile 0F S. aureus Isolates

\begin{tabular}{||c||c||c||}
\hline \hline \multirow{2}{*}{ Antimicrobials } & Resistant & Sensitive \\
\cline { 2 - 3 } & No (\%) & No (\%) \\
\hline \hline Vancomycin & $2(3.8 \%)$ & $51(96.2 \%)$ \\
\hline \hline Gentamycin & $15(28.3 \%)$ & $38(71.7 \%)$ \\
\hline \hline Tetracycline & $22(41.5 \%)$ & $31(58.5 \%)$ \\
\hline \hline Co-trimoxazole & $35(66.0 \%)$ & $18(34.0 \%)$ \\
\hline \hline Erythromycin & $37(69.8 \%)$ & $16(30.2 \%)$ \\
\hline
\end{tabular}

Out of the 53 isolates there were 36(67.9\%) S. aureus isolates resistant to Clindamycin and 17 (32.1\%) were sensitive to clindamycin. Out of $36 \mathrm{~S}$. aureus isolates resistant to Clindamycin there were 26 (72.2\%) were MRSA and 10 (27.8\%) were MSSA, while $17 \mathrm{~S}$. aureus isolate sensitive to clindamycin there were 9(52.9) were MRSA and8(47.1) were MSSA. Comparing Induced clindamycin resistance among MSSA and MRSA isolates, there was no significant difference (P-value 0.167$)$ as shown in table 2.

Table 2 : comparing the frequency distribution of D-test among $\mathrm{S}$. aureus isolates

\begin{tabular}{|c|c|c|c|}
\hline & \multicolumn{2}{|c|}{ D-test } & P-Value \\
\hline Isolates & Resistant & Sensitive & \\
\hline MSSA & $10(27.8 \%)$ & $8(47.1 \%)$ & \multirow{2}{*}{0.167} \\
\hline MRSA & $26(72.2 \%)$ & $9(52.9 \%)$ & \\
\hline Total & $36(100 \%)$ & $17(100 \%)$ & \\
\hline
\end{tabular}


The association of induced clindamycin resistance and other antibiotics was insignificant including Vancomycin, Gentamycin, tetracycline $\mathrm{P}$ value $>0.05$, while there was association with Co-trimoxazole and Erythromycin $\mathrm{P}$ value 0.009 and 0.000 , the different frequency of resistant and sensitivity of $\mathrm{S}$. aureus isolates to D-test in comparison to the other antimicrobial test as in table 3.

Table 3 : Antimicrobial profile among clindamycin sensitive and resistant

\begin{tabular}{|c|c|c|c|c|}
\hline \multirow[t]{2}{*}{ Antimicrobials } & \multicolumn{2}{|c|}{ D-test } & \multirow[t]{2}{*}{ Total } & \multirow[b]{2}{*}{ P. value } \\
\hline & Resistant & Sensitive & & \\
\hline \multicolumn{5}{|l|}{ Vancomycin } \\
\hline Resistant & $2(3.8 \%)$ & $0(0.0 \%)$ & $2(3.8 \%)$ & \multirow[t]{2}{*}{0.457} \\
\hline Sensitive & $34(64.2 \%)$ & $17(32.1 \%)$ & $51(96.2 \%)$ & \\
\hline \multicolumn{5}{|l|}{ Erythromycin } \\
\hline Resistant & $36(67.9 \%)$ & $1(1.9 \%)$ & $37(69.8 \%)$ & \multirow[t]{2}{*}{0.000} \\
\hline Sensitive & $0(0.0 \%)$ & $16(30.2 \%)$ & $16(30.2 \%)$ & \\
\hline \multicolumn{5}{|l|}{ Co-trimoxazole } \\
\hline Resistant & $28(52.8 \%)$ & 7 (13.2\%) & $35(66.0 \%)$ & \multirow[t]{2}{*}{0.009} \\
\hline Sensitive & $8(15.1 \%)$ & 10 (18.9\%) & $18(34.0 \%)$ & \\
\hline \multicolumn{5}{|l|}{ Tetracycline } \\
\hline Resistant & $14(26.4 \%)$ & $8(15.1 \%)$ & $22(41.5 \%)$ & \multirow[t]{2}{*}{0.573} \\
\hline Sensitive & $22(41.5 \%)$ & $9(17.0 \%)$ & 31 (58.5\%) & \\
\hline \multicolumn{5}{|l|}{ Gentamycin } \\
\hline Resistant & $12(22.6 \%)$ & $3(5.7 \%)$ & $15(28.3 \%)$ & \multirow[t]{2}{*}{0.237} \\
\hline Sensitive & $24(45.3 \%)$ & $14(26.4 \%)$ & 38 (71.7\%) & \\
\hline
\end{tabular}

\section{Discussion}

In this study a 53 isolates of $\mathrm{S}$. aureus were collected from different samples compose of $64.2 \%$ females and $35.8 \%$ males. Majority of isolated s. aureus were obtained from pus (50\%) followed by urine (23\%); blood and body fluids (27\%). over all clindamycin resistant S. aureus among study 36/53(67.9). Other antibiotics susceptibly profile of s. aureus included sensitive to vancomycin51 (96.2\%), Gentamycin38(71.7\%), and Tetracycline31(58.5\%). Out of the $36 \mathrm{~S}$. aureus isolates resistant to Clindamycin, 26/36 (72.2\%) were MRSA and 10/36 (27.8\%) were MSSA, while 17/53 (32.1\%) of isolates were sensitive to Clindamycin, 9/17 (53\%) MRSA and
8/17 (47 \%) MSSA. Induced clindamycin resistance showed equally distribution among MSSA and MRSA isolates, giving no significant difference as $\mathrm{P}$ - value 0.167. The association of induced clindamycin resistance and other antibiotics was insignificant including Vancomycin, Gentamycin, tetracycline $\mathrm{P}$ value 0.457 and 0.237 and 0.573 respectively. , while there was association with Co-trimoxazole and Erythromycin P value 0.009 and 0.000 , the different frequency of resistant and sensitivity of $\mathrm{S}$. aureus isolates to D-test in comparison to the other antimicrobial test.

An agreement with study was conducted in Microbiology laboratory of Nepal Medical College 
and Teaching Hospital, Kathmandu, Nepal to find the incidence of different phenotypes of MLSB resistance among S. aureus from clinical samples and their association with methicillin resistance. Of the 270 clinical isolates of S. aureus68/270(25.1\%) were MRSA. clindamycin resistance was seen in113/270(41.8\%) isolates. Resistance to clindamycin were higher in MRSA as compared to MSSA (clindamycin-resistance: 79.4\% Vs 41.8\%). (45)

Dis agreement obtained by study was aimed to detect methicillin resistance and iCR among $S$. aureus isolates, effectiveness of some commonly used antibiotics and correlation between methicillin resistance and iCR. The study included $46 S$. aureus isolates subjected to Kirby-Bauer's disk diffusion method for antibiotic susceptibility testing (AST) to estimate MRSA and resistance to some commonly used antibiotics. D-test was employed to detect iCR. Eleven of the $46(23.9 \%)$ isolates tested were MRSA. Overall, 19 (41.3\%) isolates showed of iCR. Vancomycin and linezolid were found to be 100 per cent effective. A positive Karl-Pearson's coefficient of correlation (0.89) between methicillin resistance and $\mathrm{iCR}$ was obtained (46).

\section{IV.CONCLUSION}

This study conclude that inducible clindamycin resistance in S.aureus and D.test can be used as simple and reliable method to detect clindamycin resistance in routine clinical laboratories

also comparing induced clindamycin resistance has equally distribution among MRSA and MSSA isolates giving no difference

\section{REFERENCES}

[1]. Thorlacius-Ussing L, Sandholdt H, Larsen AR, Petersen A, Benfield T. Age-Dependent Increase in Incidence of Staphylococcus aureus Bacteremia, Denmark, 2008-2015. Emerg Infect Dis. maj 2019;25(5)
[2]. Schonheyder H. C. Paul M. Placing the burden of bacteraemia in perspective. Clin Microbiol Infect. 2013; 19: 489-491

[3]. Butler-Laporte G, De L'Étoile-Morel S, Cheng MP, McDonald EG, Lee TC. MRSA colonization status as a predictor of clinical infection: A systematic review and meta-analysis. J. Infect. 2018 Dec;77(6):489-495.

[4]. Dagasso G, Conley J, Parfitt E, Pasquill K, Steele L, Laupland K. Risk factors associated with bloodstream infections in end-stage renal disease patients: a population-based study. Infect Dis (Lond). 2018 Nov - Dec;50(1112):831-836.

[5]. Arcens M, Stirnemann J, Mayor G, John G. [Epidemiology and strategy to prevent urinary catheters related complications]. Rev Med Suisse. 2018 Aug 29;14(616):1518-1521

[6]. Laupland KB, Lyytikainen O, Sogaard M, Kennedy KJ, Knudsen JD, Ostergaard C, Galbraith JC, Valiquette L, Jacobsson G, Collignon P, Schonheyder HC, International Bacteremia Surveillance Collaborative. 2013. The changing epidemiology of Staphylococcus aureus bloodstream infection: a multinational population-based surveillance study. Clin Microbiol Infect 19:465-471

[7]. Benfield T, Espersen F, Frimodt-Møller N, Jensen AG, Larsen AR, Pallesen LV, et al. Increasing incidence but decreasing in-hospital mortality of adult Staphylococcus aureus bacteraemia between 1981 and 2000. Clin Microbiol Infect. 2007;13(3):257-63.

[8]. Fowler VG, Sanders LL, Sexton DJ, Kong L, Marr KA, Gopal AK, et al. Outcome of Staphylococcus aureus bacteremia according to compliance with recommendations of infectious diseases specialists: experience with 244 patients. Clin Infect Dis Off Publ Infect Dis Soc Am. 1998;27(3):478-86.

[9]. Blyth CC, Darragh H, Whelan A, O'Shea JP, Beaman MH, McCarthy JS. Evaluation of 
clinical guidelines for the management of Staphylococcus aureus bacteraemia. Intern Med J. 2002;32(5-6):224-32.

[10]. Nissen JL, Skov R, Knudsen JD, Ostergaard C, Schonheyder HC, Frimodt-Moller N, et al. Effectiveness of penicillin, dicloxacillin and cefuroxime for penicillin-susceptible Staphylococcus aureus bacteraemia: a retrospective, propensity-score-adjusted case? control and cohort analysis. J Antimicrob Chemother. 2013;68(8):1894-900.

[11]. Rasmussen JB, Knudsen JD, Arpi M, Schonheyder HC, Benfield T, Ostergaard C. Relative efficacy of cefuroxime versus dicloxacillin as definitive antimicrobial therapy in methicillin-susceptible Staphylococcus aureus bacteraemia: a propensity-score adjusted retrospective cohort study. J Antimicrob Chemother. 2014;69(2):506-14.

[12]. Goossens H, Ferech M, Vander Stichele R, Elseviers M. Outpatient antibiotic use in Europe and association with resistance: a crossnational database study. Lancet. 2005;365(9459):579-87.

[13]. Lessa FC, Mu Y, Bamberg WM, Beldavs ZG, Dumyati GK, Dunn JR, et al. Burden of Clostridium difficile infection in the United States. N Engl J Med. 2015;372(9):825-34.

[14]. Yilmaz G, Aydin K, Iskender S, Caylan R, Koksal I. Detection and prevalence of inducible clindamycin resistance in staphylococci. J Med Microbiol. 2007; 56:342-5

[15]. Kaplan SL, Hulten KG, Gonzalez BE, Hammerman WA, Lamberth L, Versalovic J, et al. Three-year surveillance of communityacquired Staphylococcus aureus infections in children. Clin Infect Dis. 2005;40(12):1785-91. pmid:15909267

[16]. Herold BC, Immergluck LC, Maranan MC, Lauderdale DS, Gaskin RE, Boyle-Vavra S, et al. Community-acquired methicillin-resistant Staphylococcus aureus in children with no identified predisposing risk. JAMA. 1998;279(8):593-8. pmid:9486753.

[17]. Grundmann H, Aires-de-Sousa M, Boyce J, Tiemersma E. Emergence and resurgence of meticillin-resistant Staphylococcus aureus as a public-health threat. Lancet. 2006;368(9538):874-85. pmid:16950365.

[18]. Buckingham SC, McDougal LK, Cathey LD, Comeaux K, Craig AS, Fridkin SK, et al. Emergence of community-associated methicillin-resistant Staphylococcus aureus at a Memphis, Tennessee Children's Hospital. Pediatr Infect Dis J. 2004;23(7):619-24. pmid:15247599.

[19]. Fergie JE, Purcell K. Community-acquired methicillin-resistant Staphylococcus aureus infections in south Texas children. Pediatr Infect Dis J. 2001;20(9):860-3. pmid:11734764.

[20]. Naimi TS, LeDell KH, Boxrud DJ, Groom AV, Steward CD, Johnson SK, et al. Epidemiology and clonality of community-acquired methicillin-resistant Staphylococcus aureus in Minnesota, 1996-1998. Clin Infect Dis. 2001;33(7):990-6. pmid:11528570.

[21]. Liu C, Bayer A, Cosgrove SE, Daum RS, Fridkin SK, Gorwitz RJ, et al. Clinical practice guidelines by the infectious disease's society of america for the treatment of methicillinresistant Staphylococcus aureus infections in adults and children: executive summary. Clin Infect Dis. 2011;52(3):285-92. Epub 2011/01/11. pmid:21217178.

[22]. Kaplan SL. Treatment of community-associated methicillin-resistant Staphylococcus aureus infections. Pediatr Infect Dis J. 2005;24(5):4578. Epub 2005/05/07. pmid:15876948.

[23]. Marcinak JF, Frank AL. Treatment of community-acquired methicillin-resistant Staphylococcus aureus in children. Curr Opin Infect Dis. 2003;16(3):265-9. Epub 2003/06/25 pmid:12821819 
[24]. Martinez-Aguilar G, Hammerman WA, Mason EO Jr, Kaplan SL. Clindamycin treatment of invasive infections caused by communityacquired, methicillin-resistant and methicillinsusceptible Staphylococcus aureus in children. Pediatr Infect Dis J. 2003;22(7):593-8. Epub 2003/07/18. pmid:12867833.

[25]. Herigon JC, Hersh AL, Gerber JS, Zaoutis TE, Newland JG. Antibiotic management of Staphylococcus aureus infections in US children's hospitals, 1999-2008. Pediatrics. 2010;125(6): e1294-300. Epub 2010/05/19. pmid:20478934.

[26]. Lall M, Sahni AK. Prevalence of inducible clindamycin resistance in Staphylococcus aureus isolated from clinical samples. Med J Armed Forces India. 2014; 70:43-7

[27]. Nodzo SR, Boyle KK, Frisch NB. Nationwide Organism Susceptibility Patterns to Common Preoperative Prophylactic Antibiotics: What Are We Covering? J Arthroplasty. 2019 Jul;34(7S): S302-S306

[28]. Park KH, Kim DY, Lee YM, Lee MS, Kang KC, Lee JH, Park SY, Moon C, Chong YP, Kim SH, Lee SO, Choi SH, Kim YS, Woo JH, Ryu BH, Bae IG, Cho OH. Selection of an appropriate empiric antibiotic regimen in hematogenous vertebral osteomyelitis. PLoS ONE. 2019;14(2): e0211888

[29]. Struzycka I, Mazinska B, Bachanek T, BoltaczRzepkowska E, Drozdzik A, Kaczmarek U, Kochanska B, Mielczarek A, Pytko-Polonczyk J, Surdacka A, Tanasiewicz M, Waszkiel D, Hryniewicz W. Knowledge of antibiotics and antimicrobial resistance amongst final year dental students of Polish medical schools-A cross-sectional study. Eur J Dent Educ. 2019 Aug;23(3):295-303

[30]. Ma D, Chen Y, Chen T. Vaginal microbiota transplantation for the treatment of bacterial vaginosis: a conceptual analysis. FEMS Microbiol. Lett. 2019 Feb 01;366(4).
[31]. Vivek JS, Rajesh GN, Mukesh S, Manpreet K, Manpreet K, Misra RN, et al. Prevalence of inducible clindamycin resistance among community and hospital associated Staphylococcus aureus isolates in a tertiary care hospital in India. Biomed Res 2011; 22:465 9

[32]. Saderi H, Emadi B, Owlia P. Phenotypic and genotypic study of macrolide, lincosamide and streptogramin B (MLSB) resistance in clinical isolates of Staphylococcus aureus in Tehran, Iran. Med Sci Monit 2011;17:BR48 53

[33]. Reddy SP, Suresh R. Phenotypic detection of inducible clindamycin resistance among the clinical isolates of staphylococcus aureus by using the lower limit of inter disk space. J Microbiol Biotechnol Res 2012; 2:258 64

[34]. Chelae S, Laohaprertthisarn V, Phengmak M, Kongmuang U, Kalnauwakul S. Detection of inducible clindamycin resistance in staphylococci by disc diffusion induction test. J Med Assoc Thai. 2009;92(7):947-51.

[35]. Leclercq R. Mechanism of resistance to macrolides and lincosamides: nature of the resistance elements and their clinical implications. Clin Infect Dis. 2002; 34:482-92.

[36]. Siberry GK, Tekle T, Carroll K, Dick J. Failure of clindamycin treatment in methicillin resistant Staphylococcus aureus expressing inducible clindamycin resistance in vitro. C Lin Infect Dis. 2003; 37:1257-60

[37]. Deotale V, Mendiratta DK, Raut U, Narang P. Inducible clindamycin resistance in Staphylococcus aureus isolated from clinical samples. Indian J Med Microbiol. 2010; 28:1246.

[38]. Zelazny AM, Ferraro MJ, Glennen A, Hindler JF, Mann LM, Munro S, et al. Selection of strains for quality assessment of the disk induction method for detection of inducible clindamycin resistance in Staphylococci: a CLSI collaborative study. J Clin Microbiol. 2005; 43:2613-2615. 
[39]. Chelae S, Laohaprertthisarn V, Phengmak M, Kongmuang U, Kalnauwakul S. Detection of inducible clindamycin resistance in staphylococci by disk diffusion induction test. J Med Assoc Thai. 2009 Jul; 92:947-951

[40]. Fiebelkorn KR, Crawford SA, McElmeel ML, Jorgensen JH. Practical disk diffusion method for detection of inducible clindamycin resistance in Staphylococcus aureus and coagulase-negative staphylococci. J Clin Microbiol. 2003; 41:4740-744.

[41]. Steward CD, Raney PM, Morrell AK, Williams PP, McDougal LK, Jevitt L, et al. Testing for induction of clindamycin resistance in erythromycin-resistant isolates of Staphylococcus aureus. J Clin Microbiol. 2005; 43:1716-1721.

[42]. Colle J, Faster A, Marmion B, Simmons A: Practical Microbiology [Mackie \& Mc Cartney]. In.:Elsevier; 2006.

[43]. Ren CL, Morgan WJ, Konstan MW, Schechter MS, Wagener JS, Fisher KA, Regelmann WE:Presence of methicillin resistant Staphylococcus aureus in respiratory cultures from cystic fibrosis patients is associated with lower lung function. Pediatric pulmonology 2007, 42(6):513-518.

[44]. Riordan JT, Muthaiyan A, Van Voorhies W, Price CT, Graham JE, Wilkinson BJ, Gustafson JE: Response of Staphylococcus aureus to salicylate challenge. Journal of bacteriology 2007, 189(1):220-227

[45]. R. P. Adhikari, S. Shrestha, A. Barakoti \& R. Amatya Inducible clindamycin and methicillin resistant Staphylococcus aureus in a tertiary care hospital, Kathmandu, NepalBMC Infectious Diseases volume 17, Article number: 483 (2017)

[46]. Soumyadeep Ghosh and Mandira Banerjee. Methicillin resistance \& inducible clindamycin resistance in Staphylococcus aureus. Indian J Med Res v.143(3); 2016 Mar

\section{Cite this article as :}

Safana A. A. Alhady, Musa Abdalla Ali, "The Prevalence of Inducible Clindamycin Resistance Staphylococcus aureus among Various Clinical Specimens in Khartoum state Sudan", International Journal of Scientific Research in Science, Engineering and Technology (IJSRSET), Online ISSN : 2394-4099, Print ISSN : 2395-1990, Volume 8 Issue 5, pp. 13-21, September-October 2021. Available at doi $\quad$ : https://doi.org/10.32628/IJSRSET218474 Journal URL : https://ijsrset.com/IJSRSET218474

f

